\title{
Antioxidant activity, total phenolic and flavonoid content determination of some selected medicinal plants from Kavre district of Nepal
}

\author{
Rupak Kharel ${ }^{2}$ and Khaga Raj Sharma ${ }^{\text {* }}$ \\ ${ }^{1}$ Central Department of Chemistry, Tribhuvan University, Kirtipur Kathmandu, Nepal \\ ${ }^{2}$ Trinity International College, Dilli Bazaar, Kathmandu, Nepal \\ Email: khagaraj_sharma33@yahoo.com
}

\begin{abstract}
The aim of this study was to study the antioxidant potential, determination of total phenolic and flavonoid content in some selected medicinal plants from Kavre district of Nepal. The methanol extract of nine medicinal plants collected from Kavre district of Nepal, were screened for assessing bioactive phytoconstituents followed by antioxidant property, total phenolic and flavonoid content. Different plants collected were powdered and extracted with methanol, concentrated by rotatory evaporator and analyzed for the presence of phytochemicals. The antioxidant potential of the plant extracts were evaluated by DPPH radical scavenging assay. Total phenolic and total flavonoid contents were determined using Folin-Ciocalteu and aluminum chloride method respectively. The phytochemical analysis showed the presence of various secondary metabolites like alkaloids, flavonoids, polyphenols, saponins, and quinones. The extract of Spondias pinnata showed the highest radical scavenging activity up to $87.94 \pm 1.88$ with $I C_{50} 17.51 \pm 1.27 \mu \mathrm{g} / \mathrm{mL}$, followed by B. variegata, $80.63 \pm 1.06$ with $I_{50}$ value $26.55 \pm 2.61 \mu \mathrm{g} / \mathrm{mL}$. The standard, ascorbic acid has $I C_{50}$ value $20.13 \pm 1.17 \mu \mathrm{g} / \mathrm{mL}$. Further, the ethyl acetate fraction of $S$. pinnata showed the maximum radical scavenging (85.92 \pm 1.37$)$ with $I_{50}$ value $46.95 \pm 1.17 \mu \mathrm{g} / \mathrm{mL}$. Moreover, Spondias pinnatadisplayed the highest total phenolic content $48.26 \pm 1.23 \mathrm{mg} \mathrm{GAE} / \mathrm{g}$ extract while the highest flavonoid content was shown by Melia azedarach $(41.07 \pm 1.53 \mathrm{mg} Q E / \mathrm{g}$ extract).
\end{abstract}

Keywords: Antioxidant, total phenolic content, total flavonoid content, phytochemicals

\section{Introduction}

Owing to its greatly varied geographical and climatic condition of Nepal, there is huge biodiversity of plants with medicinal and aromatic values. Nepal, being located at the portion of Central Himalayas has contributed about 10 percent medicinal plants of expected 7000 species of flowering plants. ${ }^{1}$ Kavre district of Nepal is rich in biodiversity due to climatic variation and possesses varied medicinal plants. In developing countries, medicinal plants are potent sources of medicine to treat various diseases. The people living in rural areas of underdeveloped countries still depends on medicinal plants for their basic

${ }^{*}$ Corresponding author 


\section{J. Nepal Chem. Soc., Vol. 38, 2018}

health care. ${ }^{2}$ Synthetic drugs are effective to cure various diseases but on the long run, they show harmful side effects and they are expensive too. So, the drug development from natural product is promising as plants show different bioactivity to cure ailments due to the presence of bioactive compounds.

Oxidative stress needs electron pairing for their stability and thus pair with biological macromolecules such as protein, DNA, lipids and even with healthy human cells thereby gives rise to different diseases. ${ }^{3}$ In order to scavenge these free radicals, synthetic antioxidants like butylated hydroxytolune (BHT), butylated hydroxyanisole (BHA), tertiary butylated hydroxyquinone (TBHQ), etc. are being used. However, these commercially available antioxidants have side effects and are toxic in vivo. Hence, there is increased in interest for safer antioxidant from natural source to cure different diseases. ${ }^{4,5}$

Natural antioxidants, derived from plants, are secondary metabolites which scavenges the free radicals generated from the oxidation process in different cells and check different oxidative stress related maladies. Natural antioxidants are less expensive having lower toxicity and side effects. Generally, phenolic acids and flavonoids have been considered to show the bioactivity for scavenging free radicals. ${ }^{6}$ However, there might be other secondary metabolites which act as antioxidant. Natural antioxidants are less expensive having lower toxicity and side effects.

Present study mainly focused to evaluate the antioxidant potential and free radical scavenging activity of methanol extract of nine medicinal plants selected from Kavre district of Nepal. The extracts were examined for their antioxidant property by using DPPH assay. The total phenolic content and flavonoid content of each extracts were also evaluated in order to correlate either the presence of phenols and flavonoids are responsible for antioxidant property.

\section{Experimental Methods}

\section{Collection and identification of plant samples}

Different parts of nine medicinal plants were collected from the farmland of Panchkhal municipality, Kavre, Nepal; the plants were collected in the summer of May/June 2017. The plants were identified at Central Department of Botany, Tribhuvan University, Kathmandu, Nepal.

\section{Extract preparation}

Cleaned parts of plants were dried under shade at room temperature. Dried samples were chopped into pieces and then powdered using a mechanical grinder. Dried powder $(100 \mathrm{~g})$ was mixed separately in 400 $\mathrm{mL}$ methanol. The flasks were sealed tightly and extraction was done for 72 hours with occasional shaking. The obtained extracts were filtered and concentrated in a rotary evaporator. The yield of each fraction was determined and all the extracts were stored at $4{ }^{\circ} \mathrm{C}$ in a refrigerator until analyses.

\section{Preliminary phytochemical analysis}

The method employed for phytochemical screening was based on the standard protocol of Harbone et al. (1973) with some modifications. ${ }^{8}$

\section{DPPH radical scavenging assay}

Antioxidant capacity was measured by the use of free radical 2,2-diphenyl-1-picrylhydrazyl (DPPH). The ability of different plant extracts to scavenge DPPH free radical was performed by the standard 
protocol adopted by Jamuna et. al. (2012). ${ }^{9}$ Ascorbic acid of same concentrations as that of plant extract was prepared as a standard and its absorbance was measured at $517 \mathrm{~nm}$. Ascorbic acid was used as a positive control. Distilled water was used as blank. The percentage of the DPPH free radical scavenging activity was calculated using the following equation:

Where,

$\mathrm{A}_{0}=$ Absorbance of the control (DPPH solution + methanol)

$\mathrm{A}_{\mathrm{s}}=$ Absorbance of test sample

Radical scavenging $(\%)=\left[\frac{A_{0-} A_{s}}{A_{o}}\right] \times 100$

$\mathrm{The} \mathrm{IC}_{50}(50 \%$ inhibitory concentration) value was indicated as effective concentration of the sample that required to scavenge $50 \%$ of the $\mathrm{DPPH}$ free radicals. $\mathrm{IC}_{50}$ values were calculated using the inhibition curve by plotting extract concentration versus the corresponding scavenging effect.

\section{Total phenolic content (TPC)}

The total phenolic content of all selected plant extracts was estimated using Folin-Ciocaltu reagent involving gallic acid standard based on the oxidation-reduction reaction. The procedure carried out for the total phenol content was based on the standard procedure put forwarded by Kim et al. (2009) with little modification. ${ }^{10}$ TPC content concentration in extract was expressed as milligram of gallic acid equivalent per gram of dry weight (mg GAE/g) of extract which was calculated in all extracts separately using the formula; $\mathrm{C}=\mathrm{cV} / \mathrm{M}$ where, $\mathrm{C}=$ Total phenolic content compounds in $\mathrm{mg} / \mathrm{g}$, in gallic acid equivalent (GAE). $\mathrm{c}=$ concentration of gallic acid established from the calibration curve in $\mathrm{mg} / \mathrm{mL}, \mathrm{V}=$ Volume of extract in $\mathrm{mL}, \mathrm{M}=$ Weight of plant extract. The linear correlation coefficient $\left(\mathrm{R}^{2}\right)$ value and regression equation were obtained from gallic acid calibration curve. The regression equation was employed to calculate concentration of each extract. Using regression equation concentration of each extract was calculated. Thus, with the calculated value of concentration of each extract, the total phenolic content was calculated.

\section{Total flavonoid content (TFC)}

TFC of the selected plant extracts were determined by aluminum chloride colorimetric method using quercetin as standard with little modification. ${ }^{11}$ The total flavonoid content in plant extracts was expressed as milligram of quercetin equivalent per gram of dry weight (mg QE/g) of extract. The TFC was calculated with the help of standard calibration curve as described in TPC determination.

\section{Fractionation}

Crude methanol extract ( $7 \mathrm{~g}$ ) of active plant Spondias pinnata was dissolved in $150 \mathrm{~mL}$ of distilled water; it was stirred well to make it dissolved completely. This was the mother solution, which was partitioned off successively by other solvents of different polarity, i.e. hexane, DCM and ethyl acetate. To the mother solution, $200 \mathrm{~mL}$ of hexane was added. It was then continuously shaken in separating funnel and let it to stand until two layers were completely distinguishable. Hexane portion was then separated with aqueous portion. The aqueous portion is further partitioned with DCM and ethyl acetate. So, finally hexane fraction, DCM fraction and ethyl acetate fraction were obtained. In subsequent stages, each of the fractions was analyzed separately for antioxidant property.

\section{Results and Discussion}

\section{Qualitative phytochemical analysis}

Identification of major secondary metabolites of methanolic extracts was carried out in order to determine presence or absence of the different phytoconstituents. The results were evaluated by visual inspection as 


\section{J. Nepal Chem. Soc., Vol. 38, 2018}

change in color or precipitation. The table 1 shows the presence or absence of phytoconstituents in nine different plant extracts.

Table 1: Phytochemical analysis of plants extracts

\begin{tabular}{|l|cccccccccccc}
\hline Sample & SP & MA & PG & AD & VD & BV & AA & EAB & CL \\
Compounds & & & & & & & & & \\
\hline
\end{tabular}

Melia azedarach possessed all the phytochemicals which were undertaken for investigation. So, due to the presence of such secondary metabolites $M$. azedarach be the good source of such secondary metabolites. ${ }^{12}$ Spondias pinnata and Psidium guajava, were found good sources of coumarin as secondary metabolite.

\section{DPPH radical scavenging activity}

In-vitro antioxidant study of extract of different plants was performed using methanolic extracts. Of the nine selected medicinal plants, three plants extracts viz. Agerantina adenophora, Utrica dioica and Achryanthes aspera were found least antioxidant and thus are the poor sources of antioxidant. The $\mathrm{IC}_{50}$ value of each extract was calculated; lower the value of higher will be the efficiency of plant extract to scavenge the free radicals. The percentage inhibition is shown in line diagram for each plant extract comparing with standard ascorbic acid. 
J. Nepal Chem. Soc., Vol. 38, 2018
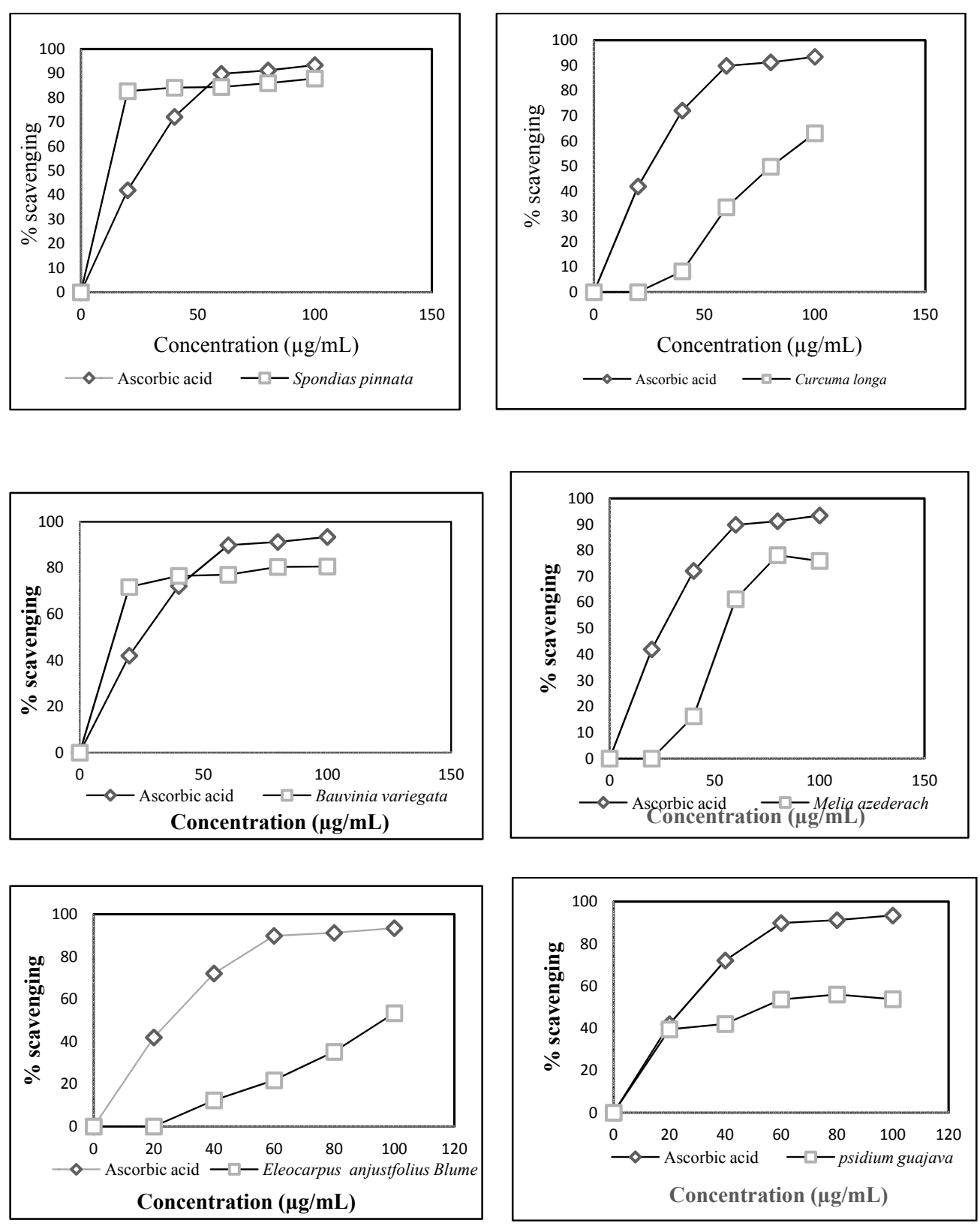

Figure 1: Percent scavenging of ascorbic acid and plants extracts

The $\mathrm{IC}_{50}$ values of some plants which showed antioxidant property were calculated and tabulated in table 2. $\mathrm{IC}_{50}$ value is the concentration of ascorbic acid or plant extracts to scavenge $50 \%$ of DPPH free radicals. 


\section{J. Nepal Chem. Soc., Vol. 38, 2018}

Table 2: $\mathrm{IC}_{50}$ values of different plants extracts

\begin{tabular}{lll}
\hline S.N. & Name of plants & $\mathrm{IC}_{50}(\mu \mathrm{g} / \mathrm{mL})$ mean $\pm \mathrm{SD}$ \\
\hline & Ascorbic acid (standard) & $20.13 \pm 0.89$ \\
2. & Spondias pinnata & $17.51 \pm 1.27$ \\
3. & Bauhina variegata & $26.55 \pm 2.61$ \\
4. & Curcuma longa & $83.50 \pm 6.42$ \\
5. & Melia azedarach & $62.04 \pm 1.55$ \\
6. & Eleocarpus anjustisfolius Blume & $104.23 \pm 3.58$ \\
7. & Psidium guajava & $70.91 \pm 2.61$ \\
\hline
\end{tabular}

The percent scavenging and $\mathrm{IC}_{50}$ of $S$. pinnata showed that the extract is a good source of an antioxidant. So, it was further fractioned so as to know the antioxidant property of other fractions. From the above results, it was found that $S$. pinnata was the most potent antioxidant among all the selected medicinal plants. So, it was further fractioned in different slovents and the results are shown by the line graph.

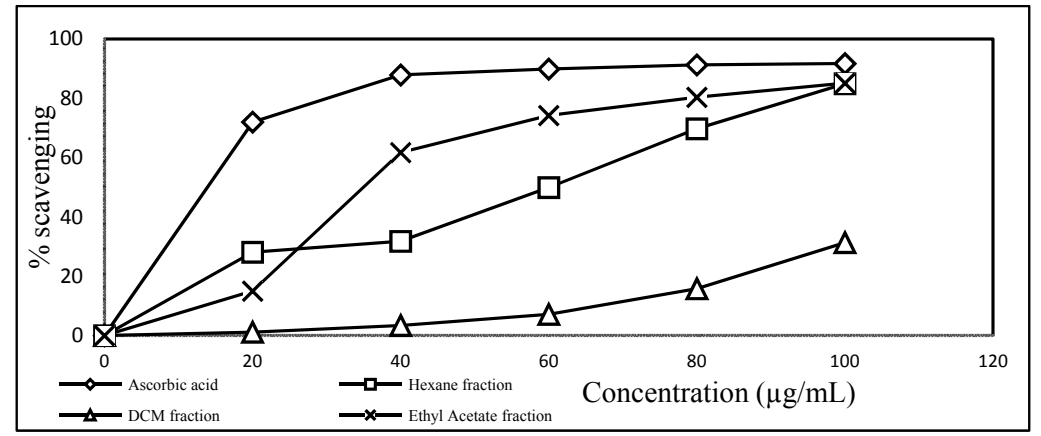

Figure 2: Percent scavenging of different fractions of Spondias pinnata

Table 3: $\mathrm{IC}_{50}$ values of different fractions of methanol extract of Spondias pinnata

\begin{tabular}{lll}
\hline S.N. & Name of plants & $\mathrm{IC}_{50}(\mu \mathrm{g} / \mathrm{mL})$ mean $\pm \mathrm{SD}$ \\
\hline 1. & Ascorbic acid & $20.13 \pm 0.89$ \\
\hline 2. & Hexane & $57.31 \pm 2.25$ \\
\hline 3. & DCM & $185.54 \pm 2.63$ \\
\hline 4. & Ethyl acetate & $46.95 \pm 1.17$
\end{tabular}

Ascorbic acid was used as standard and its $\mathrm{IC}_{50}$ value was $20.13 \pm 0.89 \mu \mathrm{g} / \mathrm{mL}$. In this study, Spondias pinnata and Bauhinia variegata showed significant antioxidant property with $\mathrm{IC}_{50} \quad 17.51 \pm 1.27 \mu \mathrm{g} / \mathrm{mL}$ and $26.55 \pm 2.61 \mu \mathrm{g} / \mathrm{mL}$ respectively. The ethyl acetate fraction of $S$. pinnata showed the maximum scavenging (85.92 \pm 1.37 ) with $\mathrm{IC}_{50}$ value $46.95 \pm 1.17 \mu \mathrm{g} / \mathrm{mL}$. Utrica dioica, Agerantina adenophora, and Achyranthes aspera did not depict antioxidant property. However, Curcuma longa, Melia azedarach, Psidium guajava and Eleocarpus anjastifolius Blume displayed moderate antioxidant property. Similarly, 
the different fractions of $S$. pinnata showed moderate antioxidant property as well. $S$. spinnata and $B$. variegata can be considered to possess significant antioxidant property which is supported by previous studies where $\mathrm{IC}_{50}$ values for scavenging were $24.48 \pm 2.31 \mu \mathrm{g} / \mathrm{mL}$ and $6.48 \pm 0.08 \mu \mathrm{g} / \mathrm{mL}$ for $S$. spinnata and B. variegata respectively. ${ }^{13,14}$ Previous studies showed that DPPH free radical scavenging activity of different fractions of $S$. pinnata was found to be concentration dependent, i.e. scavenging property increases with the increase in concentration and this finding is supported by the recent result not only in $S$. pinnata but also in rest of the plants extracts. Sharma et al. (2015) and Malik et. al. (2013) concluded the fact about the potentiality of $B$. variegata and $S$. spinnata to act as antioxidant. ${ }^{13,15}$

\section{Total phenolic content}

A calibration curve was constructed by using gallic acid as standard.

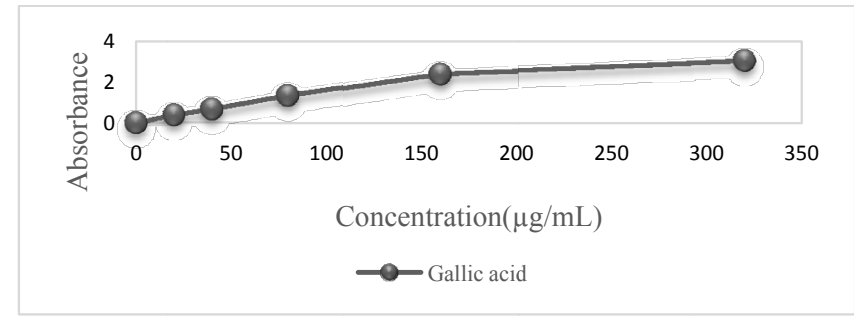

Figure 3: Gallic acid calibration curve

Table 4: Total phenolic content of different plants extracts

\begin{tabular}{llllllllll}
\hline S.N. & Name of plants & \multicolumn{2}{l}{ Absorbance } & \multicolumn{4}{c}{ TPC (mg GAE/g) } & Mean \pm SD \\
\hline & & A1 & A2 & A3 & C1 & C2 & C3 & \\
1. & Spondias pinnata & 0.742 & 0.761 & 0.744 & 47.44 & 49.67 & 47.67 & $48.26 \pm 1.23$ \\
2. & Curcuma longa & 0.54 & 0.601 & 0.554 & 28.78 & 31.78 & 26.56 & $29.04 \pm 2.62$ \\
3. & Eleocarpus anjustifolius & 0.402 & 0.351 & 0.39 & 9.67 & 4.00 & 8.33 & $7.33 \pm 2.96$ \\
4. & $\quad$ Bauhinia varigata & 0.620 & 0.572 & 0.630 & 33.89 & 28.56 & 35.00 & $32.48 \pm 3.44$ \\
5. & $\quad$ Melia azedarach & 0.461 & 0.410 & 0.451 & 16.22 & 10.56 & 15.11 & $13.96 \pm 2.99$ \\
6. & $\quad$ Achyranthes aspera & 0.401 & 0.350 & 0.373 & 9.56 & 3.89 & 6.44 & $6.63 \pm 2.84$ \\
7. & $\quad$ Psidium guajava & 0.55 & 0.673 & 0.662 & 26.11 & 39.78 & 33.89 & $33.26 \pm 6.86$ \\
\hline
\end{tabular}

The total phenolic content of extract of all selected medicinal plants showed varied results ranging from $6.63 \pm 2.84$ to $48.26 \pm 1.23 \mathrm{mg} \mathrm{GAE} / \mathrm{g}$ in Achyranthes aspera and Spondia spinnata respectively. The total phenol content of rest of plant extract lied between these two extremes. The extract of Agerantina adenophora, and Utrica dioica, whose antioxidant property was found to be nil, exhibited no significant 


\section{J. Nepal Chem. Soc., Vol. 38, 2018}

TPC. Similarly, Achyranthes aspera whose antioxidant property was nil had very low TPC and thus might not be able to show biological activity. On the other hand, those plant extracts (Spondias pinnata and Bauhinia variegata) which showed potent antioxidant property did have appreciable TPC. The present findings agree with the view that DPPH scavenging activity and phenolic content of the plant extract is related as antioxidant property of plant extract is directly correlated with its phenolic content. ${ }^{13}$

\section{Total flavonoid content (TFC)}

TFC of the selected plants extracts were determined by aluminum chloride colorimetric method involving quercetin as standard. The absorbance of quercetin (standard) was recorded from spectrophotometer is tabulated as below.

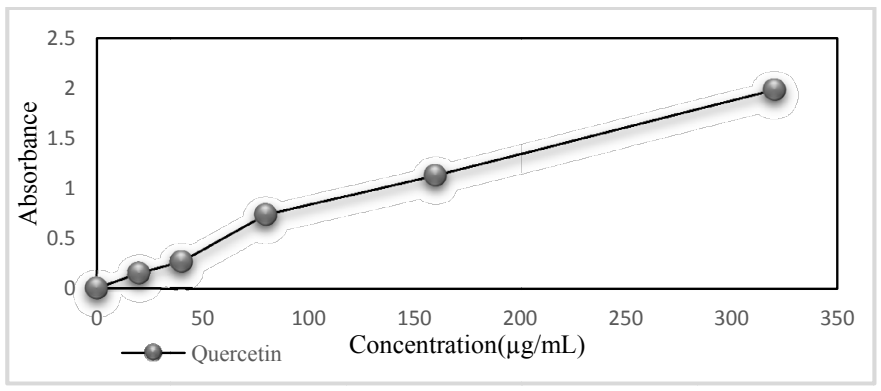

Figure 4: Standard calibration curve for quercetin

Table 5. Total flavonoid content of different plants extracts

\begin{tabular}{ccccccccc}
\hline S.N. & Name of plants & \multicolumn{3}{c}{ Absorbance } & \multicolumn{5}{c}{ TFC (mg QE/g) } \\
\hline & & A1 & A2 & A3 & C1 & C2 & C3 & Mean \pm SD \\
1. & Spondias pinnata & 0.123 & 0.133 & 0.129 & 8.39 & 10.00 & 9.35 & $9.24 \pm 0.089$ \\
2. & Curcuma longa & 0.199 & 0.222 & 0.215 & 20.65 & 24.35 & 23.23 & $22.74 \pm 1.89$ \\
3. & Banhinia variegata & 0.106 & 0.099 & 0.109 & 5.65 & 4.52 & 6.13 & $5.53 \pm 0.82$ \\
4. & Melia azedarach & 0.333 & 0.315 & 0.329 & 42.26 & 39.35 & 41.61 & $41.07 \pm 1.53$ \\
5. & Achyranthes aspera & 0.086 & 0.093 & 0.081 & 2.42 & 3.55 & 1.61 & $2.52 \pm 0.97$ \\
6. & Psidium guajava & 0.132 & 0.139 & 0.145 & 9.84 & 10.97 & 11.94 & $10.92 \pm 1.05$ \\
\hline
\end{tabular}

The total flavonoid content of different selected medicinal plants extracts was found and the results revealed that the TFC varied from $2.52 \pm 0.97 \mathrm{mg} \mathrm{QE} / \mathrm{g}$ in Achyranthes aspera to $41.07 \pm 1.53 \mathrm{mg} \mathrm{QE} / \mathrm{g}$ in Melia azedarach. All the remaining plants extract showed the TFC in between two extremes; however, Utrica dioica, Eleocarpus anjustifolius Blume, and Agerantina adenophora are the least sources of TFC. Sharma et al. (2015) and Hazra et. al. (2008) has suggested that greater flavonoid content of plant extract could be directly correlated with higher free radical scavenging property. ${ }^{13}$ present study showed the 
antioxidant activity is not only the presence of flavonoid and phenolic compounds but also due to the presence of some other organic compounds.

\section{Conclusions}

The DPPH radical scavenging activities and subsequently the $\mathrm{IC}_{50}$ values of methanolic extracts of the selected plants showed varied degree of antioxidant property; of which, S. pinnata showed appreciable percent scavenging followed by $B$. variegata. The highest percent scavenging showed by $S$. pinnata has $\mathrm{IC}_{50}$ value $17.51 \pm 1.27 \mu \mathrm{g} / \mathrm{mL}$ while the standard, ascorbic acid has $20.13 \pm 0.89 \mu \mathrm{g} / \mathrm{mL}$. Further, the ethyl acetate fraction of $S$. pinnata showed the maximum scavenging (85.92 \pm 1.37 ) with $\mathrm{IC}_{50}$ value $46.95 \pm 1.17$ $\mu \mathrm{g} / \mathrm{mL}$. The greater antioxidant property on them is credited to bioactive secondary metabolites especially phenols but not flavonoids. So, these plants could be the potential substitutes of synthetic antioxidants. Although, some medicinal plants showed significant antioxidant property, they cannot directly be referred for pharmaceutical usage. Further extensive phytochemical and pharmacological investigation must be done in order to explore the mechanism of action and to isolate and characterize lead compounds that are responsible for pharmacological properties.

\section{Acknowledgements}

Authors are thankful to the Central Department of Chemistry, Tribhuvan University for laboratory facilities and providing some chemicals. We are grateful to Prof. Dr. Mohan Sivakoti and Prof. Dr. Sangeeta Rajbhandari, Central Department of Botany, Tribhuvan University, Kathmandu, Nepal for identification of plants.

\section{References}

1. R. S. Baral, A handbook of medicinal plants in Nepal, 2005, 15, 347

2. A. Muhammad, M. S. Kabir A. H. Kabir and M. K. Hossain, Indian J. Nat. Prod. and Res., 2011, 2, 265

3. B. Hazra, S. Biswas and N. Mandal, BMC Complementary \& Alternative Med., 2008, 8

4. P. K. Ramamoorthy and A. Bono, J. of Eng. Sci. and Tech., 2007, 2, 70-80

5. V. R. Patel, P. R. Patel and S. S. Kajal, Adv. in Biol. Res., 2010, 4, 23-26

6. S. Lallianrawna and V. Ralte, Sci. Vis., 2014, 14, 128- 132

7. M. K. Kim, H. S. Lee, E. J. Kim, N. H. Won, Y. M. Chi, B. C. Kim and K. W. Lee, Food and Chem. Toxicol., 2007, 45, 1738-1744

8. J. B. Harbone, Champman and Hall. Ltd, London New York, 1973

9. S. Jamuna, S. Paulsamy and K. Karthika, J. of Appl. Pharm. Sci., 2012, 2 149-154

10. D. Gajula, M. Verghese, J. Boateng, L. T. Walker, L. Shackelford, S. R. Mentreddy and S. Cedric, Int. J. of Cancer Res., 2009, 5, 130-143

11. K. Pallab, B. Tapan, P. Tapas and K. Ramen, J. Drug Deliv. \& Ther., 2013, 3, 33-37

12. B. Pokhrel, S. Raut and S. Rijal, World J. Pharm. \& Pharm Sci., 2015, 4, 1562-1575

13. K. R. Sharma, S. K. Kalauni and S. Awale, J. Inst. Sci \& Tech., 2015, 20, 37- 41

14. B. Hazra, S. Biswas and N. Mandal, BMC Complementary \& Altern. Med., 2008, 8

15. M. K. Manik, S. M. A. Islam, M. A. Wahid, M. M. Morshed, S. Kamal, M. S. Islam and K. T. Ahmed, Can. Chem. Trans., 2013, 1, 191-201 